Louisiana State University

LSU Digital Commons

March 2019

\title{
Understanding the Social Relationships of Youth with Callous- Unemotional Traits Using Peer Nominations
}

Tatiana M. Matlasz

Louisiana State University and Agricultural and Mechanical College

Follow this and additional works at: https://digitalcommons.Isu.edu/gradschool_theses

Part of the Child Psychology Commons, and the Clinical Psychology Commons

\section{Recommended Citation}

Matlasz, Tatiana M., "Understanding the Social Relationships of Youth with Callous-Unemotional Traits Using Peer Nominations" (2019). LSU Master's Theses. 4854.

https://digitalcommons.Isu.edu/gradschool_theses/4854

This Thesis is brought to you for free and open access by the Graduate School at LSU Digital Commons. It has been accepted for inclusion in LSU Master's Theses by an authorized graduate school editor of LSU Digital Commons. For more information, please contact gradetd@lsu.edu. 
UNDERSTANDING THE SOCIAL RELATIONSHIPS OF YOUTH WITH CALLOUSUNEMOTIONAL TRAITS USING PEER NOMINATIONS

\author{
A Thesis \\ Submitted to the Graduate Faculty of the \\ Louisiana State University \\ Agricultural and Mechanical College \\ in partial fulfillment of the \\ requirements for the degree of \\ Master of Arts \\ in \\ The Department of Psychology
}

by

Tatiana Michelle Matlasz, B.A.

University at Buffalo, State University of New York, 2014

May 2019 


\section{TABLE OF CONTENTS}

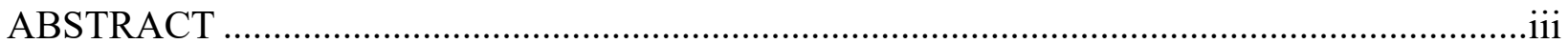

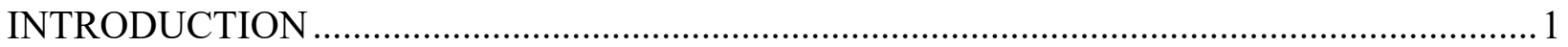

Conduct Problems with and without Elevated Callous-Unemotional Traits........................... 1

Conduct Problems and Peer Relations .............................................................................. 4

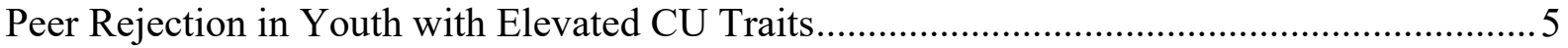

Negative Characteristics of Youth with Elevated CU Traits............................................. 6

Statement of the Problem .............................................................................................. 9

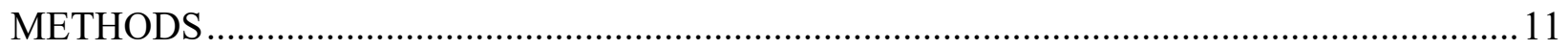

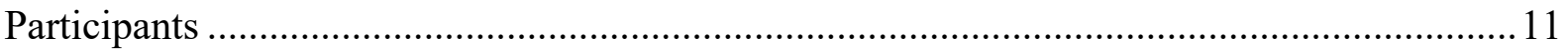

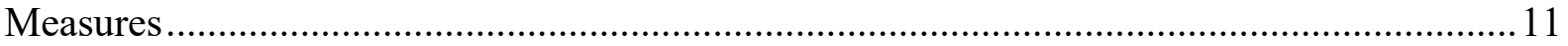

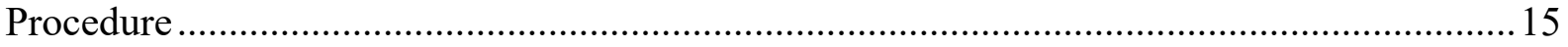

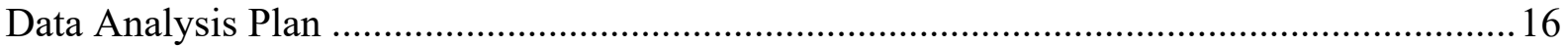

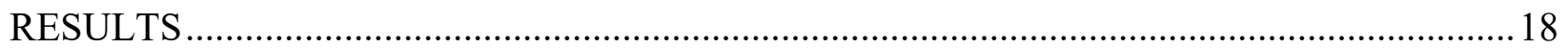

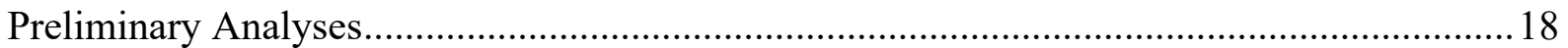

CU Traits and CP Predicting Peer Outcomes.................................................................... 19

Indirect Effects of CU Traits on Peer Rejection: Mediation Analyses..................................20

CONCLUSION

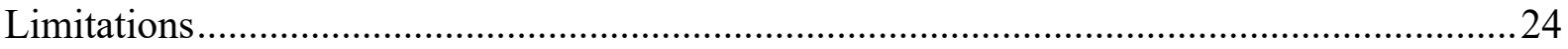

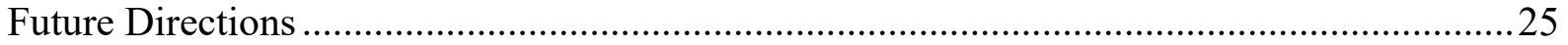

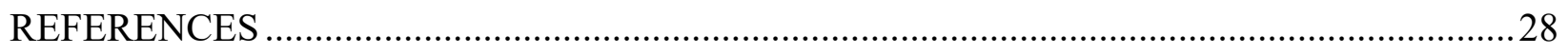

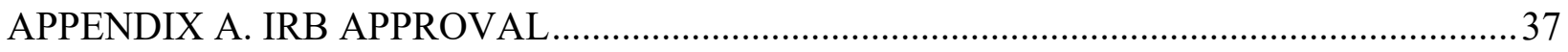

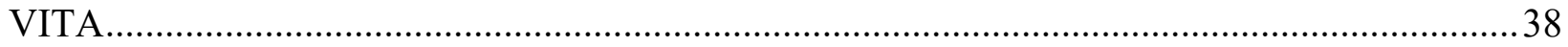




\begin{abstract}
The current study investigated the social correlates of conduct problems $(\mathrm{CP})$ and callous-unemotional $(\mathrm{CU})$ traits using peer nominations. Participants $(\mathrm{n}=289)$, drawn from a sample of $3^{\text {rd }}, 6^{\text {th }}$, and $8^{\text {th }}$ graders $\left(\mathrm{M}_{\text {age }}=11.47\right.$ years; $\left.S D=2.26\right)$, were asked to identify peers who they believed fit a number of different characteristics, in addition to individuals who they liked most and liked least. We also obtained self-, parent-, and teacher-reports of children's behaviors. Analyses extracted three primary dimensions from peer nominations, including, indicators of being mean and cold (Mean/Cold), of being aloof and untrustworthy (Not Nice), and being a leader and manipulative (Dominant/Manipulative). Results indicated that both CP and $\mathrm{CU}$ traits were associated with peer rejection. Further both $\mathrm{CP}$ and $\mathrm{CU}$ traits were associated with Mean/Cold and Not Nice peer nominations, whereas only $\mathrm{CP}$ was associated with Dominant/Manipulative nominations. Finally, bootstrap mediation analyses revealed that both the Mean/Cold and Not Nice peer dimensions accounted for a large portion of the association between $\mathrm{CP}$ and peer rejection and between $\mathrm{CU}$ traits and peer rejection. Taken together, the findings from the current study offer potential explanations for why youth with CP and CU traits are disliked by their peers, including being viewed as mean, aloof, untrustworthy, and not nice.
\end{abstract}




\section{INTRODUCTION}

Conduct problems (CP) represent the behavioral symptoms associated with the DSM-5 diagnoses of Oppositional Defiant Disorder (ODD) and Conduct Disorder (CD), and collectively represent one of the most common reasons that children and adolescents are referred to mental health clinics (Frick, 1998; Kazdin, 1995; Loeber, Burke, Lahey, Winters, \& Zera, 2000). CP include a wide range of behaviors from arguing with authority figures, lying, and deliberately annoying others to more severe behaviors such as stealing, physical aggression toward people

and animals, and destroying the property of others (American Psychiatric Association [APA], 2013). Youth with CP are quite heterogeneous with regard to not only these behavioral manifestations, but also their developmental trajectories and outcomes (Frick, Ray, Thornton, \& Kahn, 2014; Hinshaw, Lahey, \& Hart, 1993; Moffitt et al., 2008). Due to these differences, much research has been devoted to classifying youth into more uniform subgroups.

\section{Conduct Problems with and without Elevated Callous-Unemotional Traits}

The extant research has identified one such subgroup of antisocial youth by the presence of callous-unemotional (CU) traits (Frick \& Ellis, 1999; Salekin \& Frick, 2005). CU traits are derived from the adult psychopathy literature, and are conceptualized by lack of remorse or guilt, shallow or deficient affect, lack of empathy, callous use of others for personal gain, and a lack of caring about performance in important activities (Barry, Frick, DeShazo, McCoy, Ellis \& Loney, 2000; Cooke, Michie, Hart, \& Clark, 2004; Farrington, 2005; Frick, 2009; Kahn, Frick, Youngstrom, Findling, \& Youngstrom, 2012). This subgroup is important to understand because they tend to have an earlier onset of $\mathrm{CP}$, with their problems starting very early in childhood (Dandreaux \& Frick, 2009; Kahn et al., 2012; Rowe et al., 2010; Silverthorn, Frick, \& Reynolds, 2001). They also show a more severe, stable and proactively aggressive pattern of behavioral problems (Frick et al., 2003a; Frick, Stickle, Dandreaux, Farrell, \& Kimonis, 2005; Kruh, Frick, 
\& Clements, 2005; Muñoz \& Frick, 2007; Rowe et al., 2010). A significant amount of research has also shown that those with elevated CU traits are at greater risk for a variety of negative outcomes later in development, including delinquency, substance use, and school dropout, and as adults, are at greater risk for receiving a diagnosis of antisocial personality disorder (Frick et al., 2014; McMahon, Witkiewitz, \& Kotler, 2010). Thus, research clearly supports that children with $\mathrm{CP}$ who show elevated CU traits represent an important population to study. To aid in the identification of this subgroup, the specifier of "with Limited Prosocial Emotions" was recently added to the DSM-5 diagnosis of CD and is defined by the presence of significant levels of CU traits (APA, 2013).

The presence of elevated CU traits also appears to be important for designating a group of children with $\mathrm{CP}$ who show distinct etiologies leading to their behavior problems (for a complete review see Frick et al., 2014). Children with CP without CU traits primarily demonstrate problems with emotion regulation and impulse control (Frick et al., 2003; Frick et al., 2014). They are highly reactive to emotionally provocative stimuli (Kimonis, Frick, \& Barry, 2004; Loney, Frick, Clements, Ellis, \& Kerlin, 2003; Pardini, Lochman, \& Frick, 2003), and are distressed by the effects of their behaviors on others, which oftentimes result from their impulsivity (Frick et al., 2003; Frick, Lilienfeld, Ellis, Loney, \& Silverthorn, 1999; Pardini et al., 2003). Their difficulties regulating their emotions and behavior can lead to the irritability and outbursts associated with CP (e.g., Frick \& Morris, 2004). In addition, such temperamental characteristics can make the child difficult to discipline effectively, leading to more harsh and inconsistent discipline (Loeber \& Stouthamer-Loeber, 1986; Shaw, Gilliom, Ingoldsby, \& Nagin, 2003; Webster-Stratton, 1998; Wootton, Frick, Shelton, \& Silverthorn, 1997).

In contrast, children with $\mathrm{CP}$ and elevated $\mathrm{CU}$ traits have been found to exhibit very different emotional, cognitive, and familial characteristics (Frick et al., 2014). For example, in 
regards to temperament, those with elevated CU traits exhibit lower levels of fear and anxiety (Blair, 1999; Frick et al., 1999; Glenn, Raine, Venables, \& Mednick, 2007; Pardini, 2006). They also show decreased responsivity to emotionally distressing stimuli, as well as deficits in their ability to recognize emotions in others (Blair, Colledge, Murray, \& Mitchell, 2001; Dadds, El Masry, Wimalaweera, \& Guastella, 2008; Dadds et al., 2006; Fairchild, Stobbe, Van Goozen, Calder, \& Gooyer, 2010; Stevens, Charman, \& Blair, 2001; Woodworth \& Waschbusch, 2008). Further, there is evidence to suggest that they may be less emotionally responsive to the distress of others, as several studies have shown that boys with elevated CU traits reported experiencing less empathy and concern for victims of aggression compared to other children with CP (Jones, Happé, Gilbert, Burnett, \& Viding, 2010; Pardini \& Byrd, 2012). Research has also shown that this subgroup of children with CP may be less sensitive to punishment and more sensitive to reward (Frick et al., 2003a; O'Brein \& Frick, 1996). Additionally, youth with CU traits show more severe aggression that results in greater harm to others, and they are more likely to use aggression to achieve a desired goal and expect that aggression will result in positive outcomes (Frick, Cornell, Barry, Bodin, \& Dane, 2003; Kruh et al., 2005; Pardini et al., 2003). Based on these characteristics, theories have been developed to explain their development of $\mathrm{CP}$, primarily as being through a temperament characterized by low levels of reactivity to negative stimuli (e.g., distress in others, cues to punishment and threat) that make it difficult for them to develop normal levels of empathy and guilt (Frick et al., 2014).

Taken together, these findings indicate that there are clear differences in the severity and etiologies of the $\mathrm{CP}$ of children with and without CU traits. Importantly, these differences could influence how children with CP are viewed by and accepted by their peers. Unfortunately, not much research has focused on the potential differences in the peer experiences of children with CP depending on whether or not they are elevated on CU traits. 


\section{Conduct Problems and Peer Relations}

This lack of focus on the peer context of children with $\mathrm{CP}$ in the different development pathways is a critical limitation because research has consistently shown that the social interactions of children and adolescents are very important indicators of their current and future adjustment (Cicchetti, 1990; Coolahan, Fantuzzo, Mendez, \& McDermott, 2000). Specifically, research has shown that as early as preschool, positive peer relationships are associated with positive adjustment and academic success in elementary and high school (Ladd, Price, \& Hart, 1988), whereas poor peer relations in early childhood are associated with psychosocial and emotional maladjustment, delinquency and academic problems (Denham \& Holt, 1993; DeRosier, Kupersmidt, \& Patterson, 1994). Further, it is well-established that children with CP in general tend to have impaired peer relationships (Coie \& Dodge, 1998; Dodge \& Price, 1994; Huesmann, 1998; Loeber et al., 2000). Perhaps the most consistent finding is that children with $\mathrm{CP}$ are rejected by their peers, in which they have few friends and are rated as being highly “disliked” by their peers (Dodge, Bates, \& Pettit, 1990; Price \& Dodge, 1989).

This has led to a great deal of research attempting to test potential reasons for why children with $\mathrm{CP}$ are rejected by their peers. As noted above, many children with $\mathrm{CP}$ show problems regulating their emotions, which can directly lead to peer rejection (i.e., emotional outbursts leading to aggression; Poulin \& Boivin, 2000; Waschbusch, Willoughby, \& Pelham, 1998) or they can lead to problems in the child's social information processing (Crick \& Dodge, 1996). With respect to the latter, the intense emotional arousal they demonstrate can negatively influence their ability to attend to, encode, and properly interpret social cues, which may lead to an inability to meaningfully evaluate and choose how to respond in social interactions (Crick \& Dodge, 1996; Dodge \& Frame, 1982; Dodge \& Pettit, 2003). For example, research shows that children who are highly emotionally reactive have a tendency to selectively attend to hostile cues 
and interpret others' neutral behaviors as hostile or aggressive (i.e., a hostile attribution biases; Crick \& Dodge, 1996; Dodge \& Coie, 1987; Hubbard, Dodge, Cillessen, Coie, \& Schwartz, 2001). Research also suggests that emotionally reactive children with CP tend to more readily generate aggressive responses to peer provocation over non-aggressive responses (Crick \& Dodge, 1996; Dodge \& Coie, 1987; Hubbard et al., 2001).

\section{Peer Rejection in Youth with Elevated CU Traits}

Thus, there has been a substantial amount of work linking problems regulating emotions to problems with peer relationships. Such work provides several possible reasons for why children with $\mathrm{CP}$ who do not show elevated CU traits might be rejected by peers. Unfortunately, there has been very minimal research studying the peer relationships of children with $\mathrm{CU}$ traits. In one of the few studies testing the peer relationships of children with elevated CU traits, Barry and colleagues (2008) reported that CU traits were related to peer rejection, as measured by peer nominations (Barry, Barry, Deming, \& Lochman, 2008). Similarly, two other studies found comparable results across different informants (parent-, teacher-, and peer-reports; Graziano et al., 2016; Waller et al., 2016), and a final study reported that CU traits were associated with being disliked by peers, even when controlling for the child's level of CP (Piatigorsky \& Hinshaw, 2004). Thus, in the few studies assessing peer relations in youth with $\mathrm{CP}$ and elevated CU traits, it seems that this group may also experience peer rejection and therefore, it is important to consider possible reasons for these problems with peers.

As noted earlier, children with $\mathrm{CP}$ and elevated $\mathrm{CU}$ traits are aggressive (Frick et al., 2014). In fact, research suggests that youth with $\mathrm{CP}$ and elevated CU traits are often the most aggressive (Crapanzano, Frick, Childs, \& Terranova, 2011) and show a higher rate of bullying behaviors than other children with CP (Ciucci, Baroncelli, Franchi, Golmaryami, \& Frick, 2014; Fanti, 2013; Fanti, Frick, \& Georgiou, 2009; Fanti \& Kimonis, 2012; Golmaryami et al., 2016; 
Viding, Simmonds, Petrides, \& Frederickson, 2009). Consequently, like children with CP with problems in emotional regulation, youth with elevated CU traits may be rejected due to their aggressive behavior.

However, despite being aggressive and disliked by quite a few peers, children with elevated CU traits also seem to be able to make friends and often have as many friends as children without CP (Muñoz, Kerr, \& Besic, 2008). In addition, possibly the most consistent finding on the peer relationships of children with elevated CU traits is that they are much more likely to associate with deviant peers than those with CP only (Goldweber, Dmitrieva, Cauffman, Piquero, \& Steinberg, 2011; Kimonis et al., 2004). Additionally, research using peer network analysis has indicated that youth with elevated CU traits have a greater influence on their peers' deviant behavior (Kerr, Van Zalk, \& Stattin, 2012) and are more likely to lead and instigate antisocial behavior in peer groups (Thornton, Frick, Shulman, Ray, Steinberg, \& Cauffman, 2015). Thus, while being disliked by a significant number of peers, it appears that children with elevated levels of CU traits have enough social skills to maintain peer relationships (at least with deviant peers) and to influence the behavior of their peers. Therefore, what leads to their peer rejection may be less related to problems in social skills and more related to other characteristics. While this possibility has not been tested in much research, there are some clues from work on the characteristics of youth with elevated CU traits that might help to explain why they are rejected by their peers.

\section{Negative Characteristics of Youth with Elevated CU Traits}

One possible reason for the peer rejection of youth with elevated CU traits is that, despite showing normal social skills, their peers may view them as being "mean." That is, CU traits are one critical component of the larger construct of psychopathy, as noted above, and research on adults with psychopathy suggests that they are characterized by a number of traits defined as 
meanness (Patrick, Fowles, \& Krueger, 2009). Meanness is used to describe a host of attributes such as deficient empathy, aversion to and lack of close personal attachments, predatory exploitativeness, and empowerment through deliberate cruelty to others (Patrick et al., 2009). Self-report measures of meanness have been found to correlate with measures of CU traits in both adults and adolescents (Kyranides, Fanti, Sikki, \& Patrick, 2016; Patrick \& Drislane, 2015). Additionally, in a study of 86 preschoolers with externalizing behavior problems ( $69 \%$ boys; $M_{\mathrm{age}}=5.07$ years), children with elevated CU traits were more likely to be rated by peers as someone who "enjoys being mean" (Graziano et al., 2016). Compounded with the findings that youth with elevated CU traits are more likely to bully and act aggressively, it is likely that their peers may perceive them as mean.

It is also possible that children with elevated CU traits may be perceived by their peers as being dominant, which could also contribute to their rejection by some peers. As stated previously, youth high on CU traits appear to be highly influential on their peers' behavior and to be leaders when committing crimes in groups. Further, in a sample of juvenile offenders $(n=$ $156 ; 54 \%$ males; $M_{\mathrm{age}}=15.83$ ), those with elevated CU traits were more likely to endorse social goals associated with dominance and forced respect when there is conflict (Pardini, 2011). Similarly, in a sample of 347 adolescents ages 12 to $18(M=14.63)$, children with CU traits were more likely to use proactive aggression to assert dominance by "hav[ing] fights with others to show who [is] on top" and using physical force to "get others to do what [they] want" or "obtain money or things from others" (Fanti et al., 2009). Another study found that in a sample of elementary school aged children ( $51 \%$ males, $\left.M_{\text {age }}=10.31\right)$, those with elevated CU traits were less concerned about victim suffering or punishment when using aggression, and more concerned about obtaining peer dominance as a result of aggression (Pardini \& Byrd, 2012). Moreover, in adult samples, individuals elevated on psychopathic traits are often described as having a strong 
desire for power and leadership and are unlikely to worry about hurting others to obtain it (Babiak \& Hare, 2006; Babiak, Neumann, \& Hare, 2010; Hare, 1999).

Taken together, it is quite possible the youth with elevated CU traits are rejected because of a desire for dominance over others. This desire for dominance, combined with intact social skills (Grieve \& Mahar, 2010), could lead youth with elevated CU traits to be viewed as manipulative by their peers. That is, youth with CU traits tend to have greater verbal abilities than their peers (Loney, Frick, Ellis, \& McCoy, 1998) and show greater flexibility in solving social problems (Washbusch, Walsh, Andrade, King, \& Carrey, 2007) when compared to other children with CP. Further, there is evidence that adults with psychopathic traits may be perceived by their peers as being more charismatic, creative, charming and easy to talk to than others (Babiak et al., 2010). Thus, all of these skills may help persons with elevated CU traits to be more skilled and deliberate in their social interactions that are used to dominate others, leading them to being viewed as manipulative by their peers.

Finally, it is also possible that children with elevated CU traits are viewed by their peers as being aloof. As noted previously, adolescents with elevated CU traits can make friends. However, in a community sample of $7^{\text {th }}$ and $8^{\text {th }}$ grade youth and their most important peers $(\mathrm{n}=$ 667), Muñoz, Kerr, and Besic (2008) also reported that these friendships were rated as less stable and of slightly shorter duration than those of their peers who were not elevated on CU traits. They were also perceived as involving more conflict by the youth high on CU traits (Muñoz et al., 2008). Haas and colleagues (2018), using a sample of 124 students in grades 3 through 6 , reported that CU traits were associated with ratings of less perceived intimacy in their exchanges with peers and lower overall ratings of satisfaction in their peer relationships. Thus, while children with CU traits may be able to make friends, their friendships may be lower in intimacy and more transient, potentially leading them to be perceived as aloof by their peers. 


\section{Statement of the Problem}

In summary, research has shown that children and adolescents who exhibit elevated levels of CU traits represent an etiologically distinct subgroup of youth with $\mathrm{CP}$, who show a number of differences in their biological, emotional, cognitive, and familial characteristics relative to other youth with CP. However, despite these important differences in antisocial youth with and without elevated CU traits, very little research has tested differences in the peer relationships between these two groups. This is an important limitation because children and adolescents with CP show a number of problems in their peer relationships. Specifically, past research has suggested that children with CP show social skills deficits with their peers, including acting impulsively or aggressively towards others, or in other ways that annoy peers, and tend to be disliked or rejected by their prosocial classmates, leading to their association with deviant peers. Research has suggested that children with elevated CU traits demonstrate similar problems, but also seem to show a number of differences in their peer relationships compared to other children with CP only, such as showing less emotional reactivity, viewing their relationships with peers as less close, and valuing the use of aggression for positive outcomes. They also exhibit higher rates of proactive aggression, tend to blame others for their misbehavior, and self-identify as the leaders of their peer groups. Thus, while children with CP are generally at risk for peer rejection, the reasons for this rejection may be different for with and without elevated CU traits. This has not been tested in past research but was the focus of the current study.

Specifically, we tested the prediction that conduct problems would be associated with peer rejection and this would be independent of $\mathrm{CU}$ traits. In contrast, $\mathrm{CU}$ traits independent of $\mathrm{CP}$ would be associated with peer ratings of being mean, dominant, manipulative, and aloof by their peers. Finally, we test the prediction that these perceptions of being mean, dominant, 
manipulative, and aloof would mediate the association between $\mathrm{CU}$ traits and peer rejection but would not mediate the association between $\mathrm{CP}$ and peer rejection.

Specific hypotheses:

1. Peer nominations of being rejected (liked most minus liked least peer nominations) would be related to a measure of conduct problems and this would be independent of $\mathrm{CU}$ traits.

2. Peer nominations of meanness, dominance, manipulativeness, and aloofness were predicted to only be related to a measure of $\mathrm{CU}$ traits but not to the measure of $\mathrm{CP}$, after $\mathrm{CU}$ traits were controlled for.

3. CU traits were predicted to be associated with peer nominations of being rejected but this would no longer be significant when controlling for peer nominations of meanness, dominance, manipulativeness, and aloofness.

4. $\mathrm{CP}$ were predicted to retain their association with peer rejection even after controlling for $\mathrm{CU}$ traits and these peer nominations. 


\section{METHODS}

\section{Participants}

Participants were 289 children and adolescents recruited from the St. Mary and Iberia Parish school system in Louisiana, from the $3^{\text {rd }}(n=93,32.2 \%), 6^{\text {th }}(n=69,23.9 \%)$, and $8^{\text {th }}(n=$ $127,43.9 \%$ ) grades. The youth were aged eight to fifteen years old with an average age of 11.47 $(\mathrm{SD}=2.26)$ and consisted of $59.9 \%$ girls. By parental report, the sample primarily identified as Black, Afro-Caribbean, or African American (40.1\%) and Non-Hispanic Caucasian (35.3\%), with a smaller portion identifying as Biracial (12.1\%), Latino or Hispanic American (4.5\%), and other ethnic minorities (East Asian or Asian American, 2.4\%; Middle Eastern or Arab American, $0.7 \%$, Native American or Alaskan Native, $0.7 \%$; Other, $0.7 \%$ ). The remaining $3.5 \%$ of the sample did not report their ethnicity. The majority of the participants' parents were unmarried (56.7\%) and had a high school diploma or equivalent $(54.0 \%)$. The sample had a range of household incomes, with $31.8 \%$ having an income less than $\$ 20,000$ and $20.4 \%$ having incomes greater than $\$ 60,000$.

\section{Measures}

\section{Conduct problems}

The Disruptive Behavior Disorders Scale (DBD; Pelham, Gnagy, Greenslade, \& Milich, 1992) is a 45-item measure of symptoms consistent with Diagnostic and Statistical Manual of Mental Disorders ( $4^{\text {th }}$ ed.; APA) criteria for ADHD, ODD, and CD diagnoses. Items were answered on a 4-point Likert scale ("not at all" to "very much"). For the current study, only the items from the ODD and CD subscales were used in analyses. The DBD was completed by both parent and teacher. Based on the recommendation of Piacentini, Cohen, and Cohen (1992), the highest rating on each item was taken to yield a resolved score for each item, which were then summed and averaged to create the composite CP score for each child $(\alpha=.96)$. 


\section{Callous-unemotional traits}

The Inventory of Callous-Unemotional Traits (ICU; Frick, 2004). The ICU is a 24-item measure of callous, unemotional, and uncaring traits in youth. It was developed from the CU subscale of the Antisocial Process Screening Device (APSD; Frick \& Hare, 2001) and includes items such as "does not show emotions to others," "shows no remorse when he/she does something wrong," and reverse-coded items such as "is concerned about the feelings of others." Items were answered on a 4-point Likert scale $(0=$ "not at all true," $1=$ "somewhat true," $2=$ "very true," 3 = "definitely true"). The ICU has been found to be associated with antisocial behavior, conduct problems, and aggression in community samples of youth of the same age as the participants in this study (Essau, Sasagawa, \& Frick, 2006; Roose, Bijttbier, Decoene, Claes, \& Frick, 2010). For each participant, the ICU was completed by each youth and teacher, and similar to how informants were combined for $\mathrm{CP}$, a resolved score was created, in which the higher score of youth- and teacher- report was taken for each item. The ICU includes 12 positively and 12 negatively worded items and all positively worded items were reverse-scored after the highest score was taken. Items were then summed and averaged to yield the resolved score used for analyses. Participants missing more than two thirds of the items were removed from the sample. For those missing less than a third of the items, their scale score was prorated using the mean score from the available items. This ICU score showed high internal consistency $(\alpha=.90)$, and was significantly correlated with the main study variables.

\section{Peer-nominations}

Peer nomination items were developed for the purpose of this study to assess meanness, dominance, manipulativeness, and aloofness. Each dimension was assessed by 3 items with one item being worded in the positive direction. For all peer nominations, participants were allowed to nominate same- and other-gender peers within their grade at their school. They were also 
allowed to nominate themselves, but these nominations were omitted from analyses. In all grades, only the nominations of participating children were coded and used for analyses. The number of nominations received for each item was summed. Since raw scores cannot be compared across classrooms of different sizes, summed nomination scores were first standardized (Coie, Dodge, \& Coppotelli, 1982; Cillessen, 2009). Scores were standardized using the proportion score method, in which the number of nominations received was divided by the number of nominators in that grade and school to derive a score that represents a proportion of all possible nominators that chose the participant for each item (Cillessen, 2009). Proportions across all grades and schools were then multiplied by a standard, average grade size of 100. For each grade separately, these scores were then standardized (i.e., converted to z-scores), with positively-worded items being reverse-scored following standardization.

An exploratory factor analysis was then conducted to examine the structure of our peer nominations. Given that this was the first test of these items, exploratory principal factor analysis with oblique rotation was used. Initial inspection of the factor patterns indicated that the reverse-scored item, "who is usually a follower?", had low commonalities with all factors, and was therefore dropped. Further, results indicated that a three-factors showed eigenvalues over 1 and these three factors accounted for $52.67 \%$ of the variance in the peer nomination scores. The variables comprising each factor and their factor loadings are shown in Table 1.

The first factor accounted for $26.31 \%$ of the variance (eigenvalue $=3.36$ ), and included five items including, "who is mean?", "who doesn't care who they hurt?”, "who always has to get his or her own way?", "who doesn't care about having friends?", and "who is hard to get to know well?". This factor consisted of items developed to assess meanness and aloofness and was named Mean/Cold $(\alpha=.78)$. The second factor accounted for an additional $21.52 \%$ of the variance (eigenvalue $=2.72$ ) and included the three reverse-scored items, "who is nice?", "who 
can you trust?", and "who is easy to make friends with?", which together, represent a pattern of someone who is potentially not nice. Therefore, this factor was named Not Nice $(\alpha=.86)$. The third factor explained an additional $4.85 \%$ variance (eigenvalue $=1.04$ ) and is comprised of the three items designed to assess dominance and manipulativeness: "who likes to be the leader?", "who is good at getting others to do things?", and "who is good at getting what they want?".

This factor was labelled Dominant/Manipulative $(\alpha=.68)$.

Table 1. Factor Loadings of Peer Nomination Items

\begin{tabular}{lccc}
\hline & \multicolumn{3}{c}{ Factor Loadings } \\
\cline { 2 - 4 } \multicolumn{1}{c}{ Items } & $\begin{array}{c}\text { Factor 1: } \\
\text { Mean/Cold }\end{array}$ & $\begin{array}{c}\text { Factor 2: } \\
\text { Not Nice }\end{array}$ & $\begin{array}{c}\text { Factor 3: } \\
\text { Dominant/Manipulative }\end{array}$ \\
\hline Who doesn't care who they hurt? & .852 & \\
Who is mean? & .824 & \\
Who always has to get his or her way? & .637 & & \\
Who is hard to get to know well? & .510 & & \\
Who doesn't care about having friends? & .418 & .833 & .825 \\
Who is easy to make friends with? (R) & & .800 & .757 \\
Who can you trust? (R) & & & .675 \\
Who is nice? (R) & & & .526 \\
Who is good at getting what they want? & & & \\
Who is good at getting others to do things? & & & \\
Who likes to be the leader? & & & \\
\hline
\end{tabular}

Note. Positively worded items that were reverse-scored are indicated by (R).

Additionally, two sociometrics items were used to measure peer rejection as the key dependent variable in this study. These items are standard items used to assess peer rejection: "who do you like the most?" and "who do you like the least?". Nominations for both were tallied, then standardized and proportionalized in the same manner as the other peer nomination items. "Liked least" scores were subtracted from "liked most" scores to yield a total peer social status score for each child (Coie et al., 1982). This peer status score from peer nominations is the most common method for assessing peer rejection (e.g., Newcomb, Bukowski, \& Pattee, 1993). For example, past studies of children in third and fifth grades have shown that social status scores have been positively correlated with measures of aggression and negatively related to prosocial behaviors towards peers, as measured by researcher observations and teacher ratings 
(Dodge, Coie, \& Brakke, 1982). Additionally, peer rejection, as indicated by lower social preference scores, has been shown to be associated with delinquent behavior ( $r=-.21$ to -.67 ) and aggression ( $\mathrm{r}=-.29$ to -.78; Coie et al., 1990; Hartup, 1983).

\section{Procedure}

After receiving approval from the Louisiana State University Institutional Review Board and the superintendent of the Iberia parish school system, we obtained permission from the principals at the elementary and middle schools. After receiving approval from the schools, we approached teachers in the $3^{\text {rd }}, 6^{\text {th }}$, and $8^{\text {th }}$ grades. With their help, we sent a description of the study home with the children, along with parental consent forms and parent-report measures (i.e., ICU, DBD, demographics) which we anticipated taking them no more than five minutes to complete. For all participating children (i.e., those who return parental consent), teachers were given the ICU and the DBD to complete, which should have taken about five minutes for each child.

Upon receiving parental consent, children were asked for their assent to participate. All child-report measures were administered during the school day, in a group setting, on school computers. Together, all measures took on average forty-five minutes, or about the equivalence of one class period. To compensate teachers for their time and effort, and to encourage participation, we offered the school $\$ 10.00$ per participating child to go toward purchasing classroom supplies.

\section{Data Analysis Plan}

All analyses were conducted using SPSS Statistics v24. There was minimal missing data. Participants were removed for one of two reasons: if they were missing teacher report and another informant (i.e., self or parent), as either CU traits or CP could not be calculated $(\mathrm{n}=4)$; or if they left the school after parental consent was obtained, and thus, were no longer part of the 
nomination pool for their school and grade $(n=7)$. Prior to testing the main study hypotheses, zero-order correlations between demographic variables (i.e., age, gender, ethnicity, family income, and marital status) and the main study variables were tested for significance to determine if any of the demographic variables should be controlled for in the subsequent analyses.

To test that peer rejection was related to both $\mathrm{CP}$ and $\mathrm{CU}$ traits, Pearson correlations between participants' peer rejection scores and the youth-teacher resolved ICU and the parentteacher resolved DBD were run. This was followed by multiple regression analyses in which CU traits and $\mathrm{CP}$, as well as any relevant demographic variables, were entered as predictors in order to test that both variables contributed independently to the prediction of peer rejection. To test the hypothesis that being Mean/Cold, Not Nice, and Dominant/Manipulative would be related to $\mathrm{CU}$ traits and not $\mathrm{CP}$, bivariate correlations were run to show that these peer nominations were related to both variables. Then, a series of three separate simple linear regression analyses were conducted, with each peer dimension as the outcome and CU traits and CP as the predictors, again controlling for any necessary demographic variables. To test the third and fourth hypotheses, that $\mathrm{CU}$ traits would not retain their association with peer rejection after controlling for the peer dimensions, but that $\mathrm{CP}$ would, two separate regression models were run. The first model included CU traits and the peer dimensions as predictors of the social preference score, whereas the second model include CP and the peer dimensions as predictors.

Lastly, the indirect (mediated) effects of both CU traits and CP on peer preference through the peer dimensions were estimated using the PROCESS Procedure for SPSS Version 3.1 (Hayes, 2018), in which standard errors and bootstrap confidence intervals (CIs) for indirect effects were based on 1,000 bootstrap resamples with replacement (Preacher \& Hayes, 2008). This method provides a more reliable estimate of indirect effects than other mediation 
techniques, as it does not assume normal sampling distribution, better controls for Type I error, and yields higher power. 


\section{RESULTS}

\section{Preliminary Analyses}

Gender, ethnicity and marital status were each dummy coded into two categories $($ Ethnicity: Minority $=1$, White $=0 ;$ Gender: Female $=1$, Male $=0 ;$ Marital Status: Married $=1$, Not married $=0$ ). Bivariate correlations indicated that several of the demographics were significantly correlated with the main study variables (see Table 2). Specifically, age was negatively correlated with $\mathrm{CP}(r=-.12, p<.05)$, suggesting that older participants were rated as showing lower levels of CP. Both marital status and parental education were also negatively associated with CP $(r=-.13$ and -.16 , respectively, $p \mathrm{~s}<.05)$, indicating that children whose parents were married and children whose parents had higher levels of education were rated as showing lower levels of CP. Ethnicity was positively correlated with the Dominant/Manipulative peer dimension $(r=.13, p<.05)$, indicating that ethnic minorities were rated more often by their peers as showing dominant and manipulative behaviors. Lastly, gender was associated with several of the variables, suggesting that girls were more likely to be rated lower on both CU traits $(r=-.25, p<.01)$ and CP $(r=-.17, p<.01)$, received less nominations for the Not Nice peer dimension $(r=-.23, p<.01)$, and received higher ratings of social preference $(r=.16, p<.01)$. Given that gender was the only variable associated with peer nominations and the predictors, it was the only variable controlled for in the following analyses.

Table 2. Correlations Between Demographics and Main Study Variables

\begin{tabular}{lcccccc}
\hline & & \multicolumn{2}{c}{ Main Study Variables } & & \\
Demographics & CU Traits & CP & Mean/Cold & Not Nice & Dom/Manip & SocialPref \\
\cline { 2 - 7 } Age & -.05 & $-.12^{*}$ & .02 & .01 & .001 & -.01 \\
Gender & $-.25^{* *}$ & $-.17^{* *}$ & -.04 & $-.23^{* *}$ & -.04 & $.16^{* *}$ \\
Ethnicity & .11 & .03 & .06 & .04 & $.13^{*}$ & .06 \\
Marital Status & -.04 & $-.13^{*}$ & -.003 & -.06 & -.06 & .01 \\
Parental Edu & -.04 & $-.16^{*}$ & -.03 & -.07 & .02 & .05 \\
\hline
\end{tabular}

Note. $\mathrm{CU}=$ callous-unemotional; $\mathrm{CP}=$ conduct problems; Dom/Manip = Dominant/Manipulative; SocialPref $=$ Social Preference; Parental Edu = Parental Education. Gender coded as: $0=$ male, $1=$ female; Ethnicity coded as: 0 $=$ white, $1=$ minority; Marital Status coded as: $0=$ not married, $1=$ married.

$* p<.05 ; * * p<.01 ; * * * p<.001$ 
Correlations among the main study variables are presented in Table 3. As predicted, both CU traits and CP were significantly negatively associated with social preference. Additionally, the majority of the peer dimensions (i.e., Mean/Cold, Not Nice, Dominant/Manipulative) were significantly correlated with both CU traits and CP. Finally, the peer nominations for Mean/Cold and Not Nice were negatively correlated with Social Preference, but the Dominant/Manipulative dimension was not.

Table 3. Correlations Among Main Study Variables

\begin{tabular}{lcccccc}
\hline & CU Traits & CP & Mean/Cold & Not Nice & Dom/Manip & SocialPref \\
\cline { 2 - 7 } CU Traits & -- & $.47 * *$ & $.27^{* *}$ & $.27^{* *}$ & .06 & $-.29^{* *}$ \\
CP & -- & -- & $.33^{* *}$ & $.28^{* *}$ & $.14^{*}$ & $-.32^{* *}$ \\
Mean/Cold & -- & -- & -- & .10 & $.42^{* *}$ & $-.49^{* *}$ \\
Not Nice & -- & -- & -- & $-.33^{* *}$ & $-.57^{* *}$ \\
Dom/Manip & -- & -- & -- & -- & .01 \\
SocialPref & -- & -- & -- & -- & -- & -- \\
\hline
\end{tabular}

Note. $\mathrm{CU}=$ callous-unemotional; $\mathrm{CP}=$ conduct problems; Dom/Manip = Dominant/Manipulative; SocialPref $=$ Social Preference.

$* p<.05 ; * * p<.01 ; * * * p<.001$

\section{CU Traits and CP Predicting Peer Outcomes}

To test the first study hypotheses, multiple regressions were conducted with CU traits and $\mathrm{CP}$ as predictors of the various peer nominations measures, after controlling for gender. The results of these analyses are presented in Table 4. The results of these regression analyses indicated that both CU traits $(b=-.45, p<.05)$ and CP $(b=-.69, p<.001)$ negatively predicted Social Preference, suggesting that even when accounting for $\mathrm{CP}, \mathrm{CU}$ traits contribute to the prediction of peer rejection. When predicting Mean/Cold nominations, analyses again showed that both CU traits $(b=.27, p<.01)$ and $\mathrm{CP}(b=.35, p<.001)$ were significant predictors. Similarly, when predicting Not Nice nominations, both CU traits $(b=.26, p<.05)$ and CP $(b=$ $.31, p<.01)$ once again emerged as significant predictors. However, in the prediction of the last peer dimension, Dominant/Manipulative nominations, only CP $(b=.23, p<.05)$ was found to be 
a significant predictor, which suggests that $\mathrm{CU}$ traits do not add to the prediction of these peer perceptions.

Table 4. Results of Regression Analyses Predicting Peer Outcomes

\begin{tabular}{|c|c|c|c|c|c|c|c|c|}
\hline & \multicolumn{2}{|c|}{ Mean/Cold } & \multicolumn{2}{|c|}{ Not Nice } & \multicolumn{2}{|c|}{ Dom/Manip } & \multicolumn{2}{|c|}{ SocialPref } \\
\hline & $\beta(\mathrm{SE})$ & $b$ & $\beta(\mathrm{SE})$ & $b$ & $\beta(\mathrm{SE})$ & $b$ & $\beta(\mathrm{SE})$ & $b$ \\
\hline CU Traits & $.19(.09)$ & $.27 * *$ & $.15(.11)$ & $.26^{*}$ & $-.02(.10)$ & -.03 & $-.15(.19)$ & $-.45^{*}$ \\
\hline \multirow[t]{2}{*}{$\mathrm{CP}$} & $.25(.09)$ & $.35 * * *$ & $.18(.10)$ & $.31^{* *}$ & $.15(.10)$ & $.23^{*}$ & $-.24(.18)$ & $-.69 * * *$ \\
\hline & \multicolumn{2}{|c|}{$\mathrm{R}^{2}=.14$} & \multicolumn{2}{|c|}{$\mathrm{R}^{2}=.13$} & \multicolumn{2}{|c|}{$\mathrm{R}^{2}=.02$} & \multicolumn{2}{|c|}{$\mathrm{R}^{2}=.13$} \\
\hline
\end{tabular}

Note. $\beta=$ standardized beta coefficient; $b=$ unstandardized beta coefficient; $\mathrm{SE}=$ standard error. $\mathrm{CU}=$ callousunemotional; $\mathrm{CP}=$ conduct problems. Gender was controlled for in all regression analyses reported above. $* p<.05 ; * * p<.01 ; * * * p<.001$

\section{Indirect Effects of CU Traits and CP on Peer Rejection: Mediation Analyses}

Results of the mediation analyses can be found in Table 5. Two peer dimensions (i.e., Mean/Cold and Not Nice) were associated with social preference and CU traits and, as a result, were tested as potential mediators of the relationship between these two variables. Bootstrapping revealed that there was a significant indirect effect of CU traits on social preference through peer nominations of Mean/Cold and Not Nice peer nominations, $b=-1.04, \mathrm{SE}=0.16,95 \% \mathrm{CI}=$ $1.38,-0.73$. Similarly, these two peer dimensions were also associated with both social preference and $\mathrm{CP}$ so indirect effects of $\mathrm{CP}$ on social preference were also tested. Again, there was a significant indirect effect of $\mathrm{CP}$ on social preference through peer nominations of

Mean/Cold and Not Nice, $b=-0.82, \mathrm{SE}=0.14,95 \% \mathrm{CI}=-1.11,-0.57$.

Table 5. Bootstrapped Regression Analyses Examining Mediators of Social Preference Outcome

\begin{tabular}{|c|c|c|c|c|c|c|}
\hline & \multirow[b]{2}{*}{$\mathrm{R}^{2}$} & \multicolumn{3}{|c|}{ Effects } & \multicolumn{2}{|c|}{$\begin{array}{c}95 \% \text { CI of Indirect } \\
\text { Effects }\end{array}$} \\
\hline & & $\begin{array}{l}\text { Total } \\
b(\mathrm{SE})\end{array}$ & $\begin{array}{l}\text { Direct } \\
b(\mathrm{SE})\end{array}$ & $\begin{array}{l}\text { Indirect } \\
b(\mathrm{SE})\end{array}$ & Lower & Upper \\
\hline $\begin{array}{l}\text { CU } \rightarrow \text { Mean/Cold, Not Nice } \rightarrow \\
\text { SocialPref }\end{array}$ & .08 & $-.96(.19)^{* * *}$ & $.08(.15)$ & $-1.04(.16)$ & -1.38 & -.73 \\
\hline $\begin{array}{l}\text { CP } \rightarrow \text { Mean/Cold, Not Nice } \rightarrow \\
\text { SocialPref }\end{array}$ & .10 & $-.94(.16)^{* * *}$ & $-.12(.13)$ & $-.82(.14)$ & -1.11 & -.57 \\
\hline
\end{tabular}

Notes. $b=$ unstandardized beta coefficient; $\mathrm{SE}=$ standard error; $\mathrm{CI}=$ confidence interval. $\mathrm{CU}=$ callousunemotional; $\mathrm{CP}=$ conduct problems; SocialPref $=$ social preference.

$* p<.05 ; * * p<.01 ; * * * p .001$ 


\section{CONCLUSION}

The current study used peer nominations to explore the associations between a child's social acceptance and both $\mathrm{CU}$ traits and $\mathrm{CP}$. The findings suggest that both $\mathrm{CP}$ and $\mathrm{CU}$ traits predict greater levels of rejection by peers. This finding is consistent with an extensive amount of past research that has found that children with $\mathrm{CP}$ are consistently rejected by their peers (e.g., Dodge et al., 1990; Loeber et al., 2000, Price \& Dodge, 1989), as well as research finding that $\mathrm{CU}$ traits are associated with peer rejection, even when taking CP into account (Barry et al., 2008; Graziano et al., 2016; Piatigorsky \& Hinshaw, 2004; Waller et al., 2016). Thus, it is important to investigate what factors lead to these problems in peer relationships that are related to $\mathrm{CU}$ traits.

While there has been a significant amount of research suggesting that problems regulating emotion and various deficits in social information processing (e.g., hostile attribution bias) can contribute to a child with CP being rejected (Crick \& Dodge, 1996; Dodge \& Coie, 1987; Hubbard et al., 2001), there is much less research focused on explaining the association between CU traits and peer rejection. In this study, we attempted to assess several characteristics that have been associated with $\mathrm{CU}$ traits that could help to explain their association with peer rejection. First, based on previous research extended from the adult literature on psychopathy, we hypothesized that youth with elevated CU traits would be viewed by their peers as mean (Kyranides et al., 2017; Patrick \& Drislane, 2015; Graziano et al., 2016). We also assessed peer perceptions of dominance and manipulativeness, due to research indicating that youth with $\mathrm{CU}$ traits are often proactively aggressive to exert dominance (e.g., Fanti et al., 2009; Pardini \& Byrd, 2012), in addition to demonstrating seemingly intact social skills and greater social adeptness than youth with CP alone (e.g., Grieve \& Mahar, 2010; Washbusch et al., 2007). Lastly, we assessed peer perceptions of aloofness due to studies showing that children with 
elevated CU traits tend to have friendships that lack intimacy and stability (e.g., Haas et al., 2018; Muñoz et al., 2008).

Our exploratory factor analyses of these peer nominations resulted in three peer dimensions: Mean/Cold, which primarily included nominations related to meanness and aloofness, capturing heedlessness and a lack of care and detachment toward others; Not Nice, comprised of three positively-worded reverse-scored nominations related to being nice and trustworthy; and Dominant/Manipulative, with nominations related to a child liking to be the leader and being viewed as manipulative. It was particularly interesting to find distinct Mean/Cold and Not Nice dimensions. One potential explanation for this is that the traits captured by the Mean/Cold scale may be directly observed by peers without the individual having to develop close relationships with their peers; whereas items on the Not Nice scaleprior to reverse-coding - are judgments about someone's character that are not as easily observed, and may require more intimate interactions to determine. Interestingly, these two dimensions were not significantly correlated with each other $(r=.10)$ but both were highly associated with our measure of social preference $(r=-.32$ and $r=-49$, both $p<.01$ for Mean/Cold and Not Nice, respectively).

Consistent with our predictions, CU traits were significantly associated with Mean/Cold nominations. This is consistent with past research in which preschool children with elevated CU traits were rated by peers as someone who "enjoys being mean" (Graziano et al., 2016). Further, CU traits were also associated with low levels of positive peer nominations, suggesting that they are viewed by peers as not being easy to make friends with, not being trustworthy, and not being nice. This finding is supported by past work indicating that youth with elevated CU traits are more likely to use force to obtain money or things from others (Fanti et al., 2009), which may account for why their peers do not trust them. Additionally, previous work studying children 
with elevated CU traits has found that, while these youth may be able to make friends, these friendships are less successful, including being more unstable, more conflictual, and less satisfying (Haas et al., 2018; Muñoz et al., 2008). These characteristics of the friendships of youth with elevated CU traits might explain why they could be viewed as individuals who are not easy to make friends with. Importantly, as predicted, these peer perceptions accounted for a significant amount of the association between $\mathrm{CU}$ traits and peer rejection, suggesting that these characteristics play a potentially important role in the problematic peer relationships associated with CU traits.

However, contrary to predictions, these peer perceptions were also related to $\mathrm{CP}$ independent of CU traits. It is possible that this is simply due to the fact that youth with $\mathrm{CP}$ still fight, and though the reasons they fight may be different from youth with elevated CU traits (e.g., impulsivity, emotion dysregulation), their peers are still observing these behaviors and thus, they are likely to be considered as being mean and unfriendly. However, it is important to note that both $\mathrm{CP}$ and $\mathrm{CU}$ traits contributed to these peer dimensions independently, which suggests there may be an additive effect. That is, the combination of CU traits and $\mathrm{CP}$ together seems to lead to the most negative peer perceptions.

The one peer dimension that showed a differential association with $\mathrm{CP}$ and $\mathrm{CU}$ traits was being dominant (e.g., likes being a leader) and manipulative (e.g., good at getting what they want, good at getting others to do things). These peer nominations were related to CP but not $\mathrm{CU}$ traits. This finding is somewhat inconsistent with previous research that has found that children with $\mathrm{CP}$ may have difficulty interpreting social cues accurately and consequently may have trouble influencing their peers (Crick \& Dodge, 1996; Dodge \& Frame, 1982; Dodge \& Pettit, 2003), which would suggest that children with CP may be ineffective at dominating and manipulating their peers. However, it is important to note that our questions were more related 
to a desire to be a leader and to manipulate others, and did not assess whether such attempts are successful or not. Further, since it was also found that CU traits were predictive of the Not Nice factor, which includes being viewed by peers as someone who is not trustworthy, it is possible that, because children with elevated CU traits are not trusted by their peers, they are unsuccessful in manipulating or dominating them. Alternatively, it could be that youth with elevated CU traits have less interest in influencing their peers. That is, our results suggest that elevated CU traits are more related to aloofness and a lack of interest in peers, rather than an interest in dominating them. It could be that past work suggesting that $\mathrm{CU}$ traits are related to a desire for dominance focused on dominance specifically for gain (Fanti et al., 2009), whereas our nominations focused on a general desire to lead others.

\section{Limitations}

It is important to acknowledge that these findings should be interpreted in the context of several study limitations. First, only peer nominations of youth whose parents gave consent were included in the analyses, which significantly restricted the participation rate for the study. Classroom participation rates ranged from $42 \%$ to $54 \%$, with a weighted average participation rate of $49 \%$. Thus, these findings would need to replicated in other samples with higher participation rates. However, research has found that participation rates as low as $40 \%$ demonstrate acceptable reliability (Marks, Babcock, Cillessen, \& Crick, 2013). Second, a strength of the study was that we used different informants for predictors (i.e., CU traits and CP) and outcomes (i.e., peer nominations), thus eliminating inflated correlations due to shared method variance. Further, we used multiple informants in the assessment of both CU traits and CP. However, the study spanned a rather large age range and the "best" or most accurate informant may change across ages. For example, adults (i.e., parents and teachers) tend to be the most important reporters of observable, externalizing behavioral problems in younger children 
(e.g., Christiansen, Margolin, \& Sullaway, 1992), but as children age and may engage in more covert antisocial behaviors, self-reports become more important (e.g., Cantwell, Lewinsohn, Rohds, \& Seeley, 1997; Elliott, Huizinga, \& Ageton, 1985). Consequently, using the same informants for all three age groups may have reduced the validity of the assessment at certain ages. Third, the sample characteristics of the current study may influence the generalizability of the findings. Although the sample was fairly diverse in terms of race and ethnicity, family structure, and SES, the sample was recruited from the public school system in a rural area of southern Louisiana, which may limit the generalizability of the findings to other samples, especially those in more urban regions.

\section{Future Directions}

Despite these limitations, the findings provide important implications for future research and practice. First and foremost, our findings support emerging research suggesting that $\mathrm{CU}$ traits contribute to problems in peer relationships independent of their association with CP (Barry et al., 2008; Graziano et al., 2016; Piatigorsky \& Hinshaw, 2004; Waller et al., 2016). Thus, research needs to continue to explore what leads to these problems in peer relationships. In the current study, we found that CU traits were related to being nominated by peers as being mean, aloof, and untrustworthy. While these were also associated with $\mathrm{CP}, \mathrm{CU}$ traits contributed independently to their prediction, suggesting that the combination of $\mathrm{CP}$ and $\mathrm{CU}$ traits lead to the

highest rate of these nominations. Further, our findings suggest that these peer perceptions accounted for a significant and substantial amount of the association between $\mathrm{CU}$ traits and peer rejection.

Thus, these findings help to advance our knowledge of how children with CU traits may be viewed by their peers and suggests potential targets for interventions that seek to promote enhanced peer relationships in children with elevated CU traits. The findings of the present 
study suggest that one of the reasons that children with $\mathrm{CP}$ and elevated $\mathrm{CU}$ traits are disliked by their peers is because they are not considered to be nice or trustworthy; thus, interventions need to consider how to teach ways to interact with peers that can build their trust. For example, in addition to teaching basic prosocial skills to help them make friends, interventions could focus on encouraging more stability in their friendships by teaching communication and conflict resolution skills so that they are better able to keep friends. Importantly, since youth with elevated CU traits also show deficits in their ability to recognize others' emotions, they may benefit from training that helps them understand what others are feeling so that they may respond appropriately. However, not all friendships positively impact adjustment (Dishion, McCord, \& Poulin, 1999); thus, these interventions should attempt to encourage developing adaptive relationships with appropriate peers, or those without $\mathrm{CP}$, which may further encourage other peers to view them as trustworthy. Further, since children with elevated CU traits seem to be more motivated by reward than punishment (Frick et al., 2014), it would be important to motivate children with elevated CU traits to use these skills through positive change strategies. For example, rewarding them for prosocial behaviors and unprompted use of good communication skills, while consistently enforcing consequences for unwanted behaviors such as aggression.

In conclusion, the findings of this study suggest that both children with $\mathrm{CP}$ and elevated $\mathrm{CU}$ traits are rejected by their peers, and that this is at least partially due to them being viewed as being mean, aloof, and untrustworthy. Unlike children with elevated CU traits, those with $\mathrm{CP}$ may also be rejected because their peers consider them as desiring to be dominant and manipulative. Although the current study adds to the growing literature on the social relationships of youth with elevated CU traits, this area of research is still quite limited. However, the findings of this study further elucidate the potential reasons for why youth with CP 
and $\mathrm{CU}$ traits are disliked by their peers, and begins to uncover potential avenues for interventions to enhance peer acceptance. Specifically, the findings suggest the need for specialized interventions potentially focusing on strengthening these youth's abilities to make and maintain positive friendships by utilizing social skills which may ultimately lead the general peer group to view them more positively. 


\section{REFERENCES}

American Psychiatric Association. (2013). Diagnostic and statistical manual of mental disorders (5th ed.). Arlington, VA: American Psychiatric Publishing.

Babiak, P., \& Hare, R. D. (2006). Snakes in suits: When psychopaths go to work. New York, NY: Regan Books.

Babiak, P., Neumann, C. S., \& Hare, R. D. (2010). Corporate psychopathy: Talking the walk. Behavioral Sciences \& the Law, 28(2), 174-193. Doi: 10.1002/bsl.925

Barry, T. D., Barry, C. T., Deming, A. M., \& Lochman, J. E. (2008). Stability of psychopathic characteristics in childhood: The influence of social relationships. Criminal Justice and Behavior, 35(2), 244-262. doi: 10.1177/0093854807310508

Barry, C. T., Frick, P. J., DeShazo, T. M., McCoy, M. G., Ellis, M. \& Loney, B. R. (2000). The importance of callous-unemotional traits for extending the concept of psychopathy to children. Journal of Abnormal Psychology, 109 (2), 335-340. doi: 10.1037/0021843X.109.2.335

Blair, R. J. R. (1999). Responsiveness to distress cues in the child with psychopathic tendencies. Personality and individual differences, 27(1), 135-145. doi: 10.1016/S01918869(98)00231-1

Blair, R. J. R., Colledge, E., Murray, L., \& Mitchell, D. G. V. (2001). A selective impairment in the processing of sad and fearful expressions in children with psychopathic tendencies. Journal of abnormal child psychology, 29(6), 491-498. doi: 10.1023/A:1012225108281

Cantwell, D. P., Lewinsohn, P. M., Rohds, P., \& Seeley, J. R. (1997). Correspondence between adolescent report and parent report of psychiatric diagnostic data. Journal of the American Academy of Child and Adolescent Psychiatry, 36, 610-619.

Christensen, A., Margolin, G., \& Sullaway, M. (1992). Interparental agreement on child behavior problems. Psychological Assessment, 4(4), 419.

Cicchetti, D. (1990). Perspectives on the interface between normal and atypical development. Development and Psychopathology, 2(4), 329-333. doi:10.1017/S0954579400005757

Cillessen, A. H. N. (2009). Sociometric methods. In K. H. Rubin, W. M. Bukowski, \& B. Laursen (Eds.), Social, emotional, and personality development in context. Handbook of peer interactions, relationships, and groups (pp. 82-99). New York, NY, US: Guilford Press.

Ciucci, E., Baroncelli, A., Franchi, M., Golmaryami, F. N., \& Frick, P. J. (2014). The association between callous-unemotional traits and behavioral and academic adjustment in children: 
Further validation of the Inventory of Callous-Unemotional Traits. Journal of Psychopathology and Behavioral Assessment, 36(2), 189-200.

Coie, J. D., \& Dodge, K. A. (1998). Aggression and antisocial behavior. In W. Damon (Series Ed.) \& N. Eisenberg (Vol. Ed.), Handbook of child psychology: Vol. 3. Social, emotional, and personality development (5th ed., pp. 779-862). New York: Wiley.

Coie, J. D., Dodge, K. A., \& Coppotelli, H. (1982). Dimensions and types of social status: A cross-age perspective. Developmental Psychology, 18(4), 557.

Coie, J. D., Dodge, K. A., \& Kupersmidt, J. B. (1990). Peer group behavior and social status. In S. R. Asher \& J. D. Coie (Eds.), Peer rejection in childhood (pp. 17-59). Cambridge, U.K.: Cambridge University Press.

Cooke, D. J., Michie, C., Hart, S. D., \& Clark, D. A. (2004). Reconstructing psychopathy: Clarifying the significance of antisocial and socially deviant behavior in the diagnosis of psychopathic personality disorder. Journal of Personality Disorders, 18(4), 337-357. doi: 10.1521/pedi.2004.18.4.337

Coolahan, K., Fantuzzo, J., Mendez, J., \& McDermott, P. (2000). Preschool peer interactions and readiness to learn: Relationships between classroom peer play and learning behaviors and conduct. Journal of Educational Psychology, 92(3), 458. doi: 10.1037/00220663.92.3.458

Crapanzano, A. M., Frick, P. J., Childs, K., \& Terranova, A. M. (2011). Gender differences in the assessment, stability, and correlates to bullying roles in middle school children. Behavioral Sciences \& the Law, 29(5), 677-694. doi: 10.1002/bsl.1000

Crick, N. R., \& Dodge, K. A. (1996). Social information-processing mechanisms in reactive and proactive aggression. Child Development, 67(3), 993-1002. doi: 10.1111/j.14678624.1996.tb01778.x

Dadds, M. R., El Masry, Y., Wimalaweera, S., \& Guastella, A. J. (2008). Reduced eye gaze explains "fear blindness" in childhood psychopathic traits. Journal of the American Academy of Child \& Adolescent Psychiatry, 47(4), 455-463. doi: 10.1097/CHI.0b013e31816407f1

Dadds, M. R., Perry, Y., Hawes, D. J., Merz, S., Riddell, A. C., Haines, D. J., ... \& Abeygunawardane, A. I. (2006). Attention to the eyes and fear-recognition deficits in child psychopathy. The British Journal of Psychiatry, 189(3), 280-281. doi: 10.1192/bjp.bp.105.018150

Dandreaux, D. M., \& Frick, P. J. (2009). Developmental pathways to conduct problems: A further test of the childhood and adolescent-onset distinction. Journal of Abnormal Child Psychology, 37(3), 375. doi: 10.1007/s10802-008-9261-5

Denham, S. A., \& Holt, R. W. (1993). Preschoolers' likability as cause or consequence of their social behavior. Developmental Psychology, 29, 271-271. 
DeRosier, M. E., Kupersmidt, J. B., \& Patterson, C. J. (1994). Children's academic and behavioral adjustment as a function of the chronicity and proximity of peer rejection. Child Development, 65(6), 1799-1813. doi: 10.1111/j.14678624.1994.tb00850.x

Dishion, T. J., McCord, J., \& Poulin, F. (1999). When interventions harm: Peer groups and problem behavior. American Psychologist, 54(9), 755.

Dodge, K. A., Bates, J. E., \& Pettit, G. S. (1990). Mechanisms in tie cycle of violence. Science, 250, 1678-1683.

Dodge, K. A., \& Coie, J. D. (1987). Social-information-processing factors in reactive and proactive aggression in children's peer groups. Journal of Personality and Social Psychology, 53(6), 1146. doi: 10.1037/0022-3514.53.6.1146

Dodge, K. A., Coie, J. D., \& Brakke, N. P. (1982). Behavior patterns of socially rejected and neglected preadolescents: The roles of social approach and aggression. Journal of Abnormal Child Psychology, 10(3), 389-409.

Dodge, K. A., \& Frame, C. L. (1982). Social cognitive biases and deficits in aggressive boys. Child Development, 620-635. doi: 10.2307/1129373

Dodge, K. A., \& Pettit, G. S. (2003). A biopsychosocial model of the development of chronic conduct problems in adolescence. Developmental Psychology, 39(2), 349.

Dodge, K. A., \& Price, J. M. (1994). On the relation between social information processing and socially competent behavior in early school-aged children. Child Development, 65(5), 1385-1397. doi: 10.1111/j.1467-8624.1994.tb00823.x

Elliott, D. S., Huizinga, D., \& Ageton, S. S. (1985). Explaining delinquency and drug use. Beverly Hills, CA: Sage.

Essau, C. A., Sasagawa, S., \& Frick, P. J. (2006). Callous-unemotional traits in a community sample of adolescents. Assessment, 13(4), 454-469.

Fairchild, G., Stobbe, Y., Van Goozen, S. H. M., Calder, A. J., \& Gooyer, I. M. (2010). Facial expression recognition, fear conditioning, and startle modulation in female subjects with conduct disorder. Biological Psychiatry, 68, 272-279. doi:

10.1016/j.biopsych.2010.02.019

Fanti, K. A., Frick, P. J., \& Georgiou, S. (2009). Linking callous-unemotional traits to instrumental and non-instrumental forms of aggression. Journal of Psychopathology and Behavioral Assessment, 31(4), 285. Doi: 10.1007/s10862-008-9111-3

Fanti, K. A., \& Kimonis, E. R. (2012). Bullying and victimization: The role of conduct problems and psychopathic traits. Journal of Research on Adolescence, 22(4), 617-631. Doi: 10.1111/j.1532-7795.2012.00809.x 
Farrington, D. P. (2005). Childhood origins of antisocial behavior. Clinical Psychology and Psychotherapy, 12(3), 177-190. doi: 10.1002/cpp.448

Frick, P. J. (1998). Conduct disorders and severe antisocial behavior. New York: Plenum Press.

Frick, P. J. (2009). Extending the construct of psychopathy to youths: Implications for understanding, diagnosing, and treating antisocial children and adolescents. Canadian Journal of Psychiatry, 12, 803-812.

Frick, P. J., Cornell, A. H., Bodin, S. D., Dane, H. E., Barry, C. T., \& Loney, B. R. (2003). Callous-unemotional traits and developmental pathways to severe conduct problems. Developmental Psychology, 39(2), 246. doi: 10.1037/0012-1649.39.2.246

Frick, P. J., Cornell, A. H., Barry, C. T., Bodin, S. D., \& Dane, H. E. (2003). Callousunemotional traits and conduct problems in the prediction of conduct problem severity, aggression, and self-report of delinquency. Journal of Abnormal Child Psychology, 31(4), 457-470. doi: 10.1023/A:1023899703866

Frick, P. J., \& Ellis, M. (1999). Callous-unemotional traits and subtypes of conduct disorder. Clinical Child and Family Psychology Review, 2(3), 149-168.

Frick, P. J., \& Hare, R. D. (2001). Antisocial process screening device: APSD. Toronto: MultiHealth Systems.

Frick, P. J., Lilienfeld, S. O., Ellis, M., Loney, B., \& Silverthorn, P. (1999). The association between anxiety and psychopathy dimensions in children. Journal of Abnormal Child Psychology, 27(5), 383-392. doi: 10.1023/A:1021928018403

Frick, P. J., \& Morris, A. S. (2004). Temperament and developmental pathways to conduct problems. Journal of Clinical Child and Adolescent Psychology, 33(1), 54-68. doi: 10.1207/S15374424JCCP3301_6

Frick, P. J., Ray, J. V., Thornton, L. C., \& Kahn, R. E. (2014). Can callous-unemotional traits enhance the understanding, diagnosis, and treatment of serious conduct problems in children and adolescents? A comprehensive review. Psychological Bulletin, 140(1), 1. doi: $10.1111 /$ jcpp. 12152

Frick, P. J., Stickle, T. R., Dandreaux, D. M., Farrell, J. M., \& Kimonis, E. R. (2005). Callousunemotional traits in predicting the severity and stability of conduct problems and delinquency. Journal of Abnormal Child Psychology, 33, 471-487. doi: 10.1007/s10648005-5728-9

Glenn, A. L., Raine, A., Venables, P. H., \& Mednick, S. A. (2007). Early temperament and psychophysiological precursors of adult psychopathic personality. Journal of Abnormal Psychology, 116, 508-518. doi: 10.1037/0021-843X.116.3.508 
Goldweber, A., Dmitrieva, J., Cauffman, E., Piquero, A. R., \& Steinberg, L. (2011). The development of criminal style in adolescence and young adulthood: Separating the lemmings from the loners. Journal of Youth and Adolescence, 40(3), 332-346. doi: $10.1007 / \mathrm{s} 10964-010-9534-5$

Golmaryami, F. N., Frick, P. J., Hemphill, S. A., Kahn, R. E., Crapanzano, A. M., \& Terranova, A. M. (2016). The social, behavioral, and emotional correlates of bullying and victimization in a school-based sample. Journal of Abnormal Child Psychology, 44(2), 381-391. doi: 10.1007/s10802-015-9994-x

Graziano, P. A., Ros, R., Haas, S., Hart, K., Slavec, J., Waschbusch, D., \& Garcia, A. (2016). Assessing callous-unemotional traits in preschool children with disruptive behavior problems using peer reports. Journal of Clinical Child \& Adolescent Psychology, 45(2), 201-214. doi: 10.1080/15374416.2014.971460

Grieve, R., \& Mahar, D. (2010). The emotional manipulation-psychopathy nexus: Relationships with emotional intelligence, alexithymia and ethical position. Personality and Individual Differences, 48(8), 945-950. doi: 10.1016/j.paid.2010.02.028

Haas, S. M., Becker, S. P., Epstein, J. N., \& Frick, P. J. (2018). Callous-unemotional traits are uniquely associated with poorer peer functioning in school-aged children. Journal of Abnormal Child Psychology, 46(4), 781-793.

Hare, R. D. (1999). Without conscience: The disturbing world of the psychopaths among us. Guilford Press.

Hartup, W. W. (1983). Peer relations. In E. M. Hetherington (Ed.), Handbook of child psychology (Vol. 4): Socialization, personality, and social development (pp. 103-198). New York: Wiley.

Hinshaw, S. P., Lahey, B. B., \& Hart, E. L. (1993). Issues of taxonomy and comorbidity in the development of conduct disorder. Development and Psychopathology, 5(1-2), 31-49. doi: $10.1017 / \mathrm{S} 0954579400004247$

Hubbard, J. A., Dodge, K. A., Cillessen, A. H., Coie, J. D., \& Schwartz, D. (2001). The dyadic nature of social information processing in boys' reactive and proactive aggression. Journal of Personality and Social Psychology, 80(2), 268. doi: 10.1037//0022-3514.80.2.268

Huesmann, L. R. (1998). The role of social information processing and cognitive schema in the acquisition and maintenance of habitual aggressive behavior. In R. G. Geen \& E. Donnerstein (Eds.), Human aggression: Theories, research, and implications for social policy (pp. 73-109). New York, NY: Academic Press.

Jones, A. P., Happé, F. G., Gilbert, F., Burnett, S., \& Viding, E. (2010). Feeling, caring, knowing: different types of empathy deficit in boys with psychopathic tendencies and autism spectrum disorder. Journal of Child Psychology and Psychiatry, 51(11), 11881197. doi: 10.1111/j.1469-7610.2010.02280.x 
Kahn, R. E., Frick, P. J., Youngstrom, E., Findling, R. L., \& Youngstrom, J. K. (2012). The effects of including a callous-unemotional specifier for the diagnosis of conduct disorder. Journal of Child Psychology and Psychiatry, 53, 271-282. doi: 10.1111/j.14697610.2011.02463.x

Kazdin, A. E. (1995). Conduct disorders in childhood and adolescence (Vol. 9). Sage.

Kerr, M., Van Zalk, M., \& Stattin, H. (2012). Psychopathic traits moderate peer influence on adolescent delinquency. Journal of Child Psychology and Psychiatry, 53(8), 826-835. doi: 10.1111/j.1469-7610.2011.02492.x

Kimonis, E. R., Frick, P. J., \& Barry, C. T. (2004). Callous-unemotional traits and delinquent peer affiliation. Journal of Consulting and Clinical Psychology, 72(2), 1-11. doi: 10.1037/0022-006X.72.6.956

Kruh, I. P., Frick, P. J., \& Clements, C. B. (2005). Historical and personality correlates to the violence patterns of juveniles tried as adults. Criminal Justice and Behavior, 32(1), 69 96. doi: 10.1177/0093854804270629

Kyranides, M. N., Fanti, K. A., Sikki, M., \& Patrick, C. J. (2017). Triarchic dimensions of psychopathy in young adulthood: Associations with clinical and physiological measures after accounting for adolescent psychopathic traits. Personality Disorders: Theory, Research, and Treatment, 8(2), 140. doi: 10.1037/per0000193

Ladd, G. W., Price, J. M., \& Hart, C. H. (1988). Predicting preschoolers' peer status from their playground behaviors. Child Development, 986-992.

Loeber, R., Burke, J. D., Lahey, B. B., Winters, A., \& Zera, M. (2000). Oppositional defiant and conduct disorder: A review of the past 10 years, part I. Journal of the American Academy of Child \& Adolescent Psychiatry, 39(12), 1468-1484.

Loeber, R., \& Stouthamer-Loeber, M. (1986). Family factors as correlates and predictors of juvenile conduct problems and delinquency. Crime and Justice, 7, 29-149.

Loney, B. R., Frick, P. J., Clements, C. B., Ellis, M. L., \& Kerlin, K. (2003). Callousunemotional traits, impulsivity, and emotional processing in adolescents with antisocial behavior problems. Journal of Clinical Child and Adolescent Psychology, 32(1), 66-80.

Loney, B. R., Frick, P. J., Ellis, M., \& McCoy, M. G. (1998). Intelligence, callous-unemotional traits, and antisocial behavior. Journal of Psychopathology and Behavioral Assessment, 20(3), 231-247. doi: 10.1023/A:1023015318156

Marks, P. E., Babcock, B., Cillessen, A. H., \& Crick, N. R. (2013). The effects of participation rate on the internal reliability of peer nomination measures. Social Development, 22(3), 609-622. 
McMahon, R. J., Witkiewitz, K., \& Kotler, J. S. (2010). Predictive validity of callousunemotional traits measured in early adolescence with respect to multiple antisocial outcomes. Journal of Abnormal Psychology, 119(4), 752. doi: 10.1037/a0020796

Moffitt, T. E., Arseneault, L., Jaffee, S. R., Kim-Cohen, J., Koenen, K. C., Odgers, C. L., ... \& Viding, E. (2008). Research Review: DSM-V conduct disorder: Research needs for an evidence base. Journal of Child Psychology and Psychiatry, 49(1), 3-33. doi: 10.1111/j.1469-7610.2007.01823.x

Muñoz, L. C., \& Frick, P. J. (2007). The reliability, stability, and predictive utility of the selfreport version of the antisocial process screening device. Scandinavian Journal of Psychology, 48(4), 299-312. doi: 10.1111/j.1467-9450.2007.00560.x

Muñoz, L. C., Kerr, M., \& Besic, N. (2008). The peer relationships of youths with psychopathic personality traits: A matter of perspective. Criminal Justice and Behavior, 35(2), 212227. doi: 10.1177/0093854807310159

Newcomb, A. F., Bukowski, W. M., \& Pattee, L. (1993). Children's peer relations: A metaanalytic review of popular, rejected, neglected, controversial, and average sociometric status. Psychological Bulletin, 113(1), 99-128. doi:10.1037/0033-2909.113.1.99

O'Brien, B. S., \& Frick, P. J. (1996). Reward dominance: Associations with anxiety, conduct problems, and psychopathy in children. Journal of abnormal child psychology, 24(2), 223-240. doi: 10.1007/BF01441486

Pardini, D. A. (2006). The callousness pathway to severe violent delinquency. Aggressive Behavior, 32(6), 590-598. doi: 10.1002/ab.20158

Pardini, D. (2011). Perceptions of social conflicts among incarcerated adolescents with callousunemotional traits: 'You're going to pay. It's going to hurt, but I don't care.' Journal of child psychology and psychiatry, 52(3), 248-255. doi: 10.1111/j.1469-7610.2010.02336.x

Pardini, D. A., \& Byrd, A. L. (2012). Perceptions of aggressive conflicts and others' distress in children with callous-unemotional traits: 'I'll show you who's boss, even if you suffer and I get in trouble.' Journal of Child Psychology and Psychiatry, 53(3), 283-291. doi: 10.1111/j.1469-7610.2011.02487.x

Pardini, D. A., Lochman, J. E., \& Frick, P. J. (2003). Callous/unemotional traits and socialcognitive processes in adjudicated youths. Journal of the American Academy of Child \& Adolescent Psychiatry, 42(3), 364-371. doi: 10.1097/00004583-200303000-00018

Patrick, C. J., \& Drislane, L. E. (2015). Triarchic model of psychopathy: Origins, operationalizations, and observed linkages with personality and general psychopathology. Journal of personality, 83(6), 627-643. doi: 10.1111/jopy.12119

Patrick, C. J., Fowles, D. C., \& Krueger, R. F. (2009). Triarchic conceptualizations of psychopathy: Developmental origins of disinhibition, boldness, and meanness. Development and Psychopathology, 21, 913-938. doi: 10.1017=s0954579409000492 
Pelham Jr., W. E., Gnagy, E. M., Greenslade, K. E., \& Milich, R. (1992). Teacher ratings of DSM-III-R symptoms for the disruptive behavior disorders. Journal of the American Academy of Child \& Adolescent Psychiatry, 31(2), 210-218.

Piacentini, J. C., Cohen, P., \& Cohen, J. (1992). Combining discrepant diagnostic information from multiple sources: are complex algorithms better than simple ones?. Journal of Abnormal Child Psychology, 20(1), 51-63.

Piatigorsky, A., \& Hinshaw, S. P. (2004). Psychopathic traits in boys with and without attentiondeficit/hyperactivity disorder: concurrent and longitudinal correlates. Journal of Abnormal Child Psychology, 32(5), 535-550.

Poulin, F., \& Boivin, M. (2000). Reactive and proactive aggression: evidence of a two-factor model. Psychological Assessment, 12(2), 115. doi: 10.1037/1040-3590.12.2.115

Preacher, K. J., \& Hayes, A. F. (2008). Asymptotic and resampling strategies for assessing and comparing indirect effects in multiple mediator models. Behavior Research Methods, $40(3), 879-891$.

Price, J. M., \& Dodge, K. A. (1989). Reactive and proactive aggression in childhood: Relations to peer status and social context dimensions. Journal of Abnormal Child Psychology, 17(4), 455-471. doi: 10.1007/BF00915038

Roose, A., Bijttebier, P., Decoene, S., Claes, L., \& Frick, P. J. (2010). Assessing the affective features of psychopathy in adolescence: a further validation of the inventory of callous and unemotional traits. Assessment, 17(1), 44-57.

Rowe, R., Maughan, B., Moran, P., Ford, T., Briskman, J., \& Goodman, R. (2010). The role of callous and unemotional traits in the diagnosis of conduct disorder. Journal of Child Psychology and Psychiatry, 51(6), 688-695. doi: 10.1111/j.1469-7610.2009.02199.x

Salekin, R. T., \& Frick, P. J. (2005). Psychopathy in children and adolescents: The need for a developmental perspective. Journal of Abnormal Child Psychology, 33(4), 403-409. doi: $10.1007 / \mathrm{s} 10802-005-5722-2$

Shaw D. S., Gilliom, M., Ingoldsby, E. M., \& Nagin, D. S. (2003). Trajectories leading to school-age conduct problems. Developmental Psychology, 39, 189-200. doi: 10.1037/0012-1649.39.2.189

Silverthorn, P., Frick, P.J., \& Reynolds, R. (2001). Timing of onset and correlates of severe conduct problems in adjudicated girls and boys. Journal of Psychopathology and Behavioral Assessment, 23, 171-181. doi: 10.1023/A:101091730

Stevens, D., Charman, T., \& Blair, R. J. R. (2001). Recognition of emotion in facial expressions and vocal tones in children with psychopathic tendencies. The Journal of genetic psychology, 162(2), 201-211. doi: 10.1080/00221320109597961 
Thornton, L. C., Frick, P. J., Shulman, E. P., Ray, J. V., Steinberg, L., \& Cauffman, E. (2015). Callous-unemotional traits and adolescents' role in group crime. Law and Human Behavior, 39(4), 368. doi: 10.1037/lhb0000124

Viding, E., Simmonds, E., Petrides, K. V., \& Frederickson, N. (2009). The contribution of callous-unemotional traits and conduct problems to bullying in early adolescence. Journal of Child Psychology and Psychiatry, 50(4), 471-481. Doi: 10.1111/j.1469-7610.2008.02012.x

Waller, R., Baskin-Sommers, A. R., \& Hyde, L. W. (2016). Examining predictors of callous unemotional traits trajectories across adolescence among high-risk males. Journal of Clinical Child \& Adolescent Psychology, 1-14. doi: 10.1080/15374416.2015.1102070

Waschbusch, D. A., Walsh, T. M., Andrade, B. F., King, S., \& Carrey, N. J. (2007). Social problem solving, conduct problems, and callous-unemotional traits in children. Child Psychiatry and Human Development, 37(4), 293.

Waschbusch, D. A., Willoughby, M. T., \& Pelham, W. E. (1998). Criterion validity and the utility of reactive and proactive aggression: comparisons to ADHD, ODD, CD, and other measures of functioning. Journal of Clinical Child Psychology, 27, 396-405.

Webster-Stratton, C. (1998). Preventing conduct problems in Head Start children: Strengthening parenting competencies. Journal of Consulting and Clinical Psychology, 66, 715-730. doi: 10.1037/0022-006X.66.5.715

Woodworth, M., \& Waschbusch, D. (2008). Emotional processing in children with conduct problems and callous/unemotional traits. Child: Care, Health and Development, 34(2), 234-244.

Wootton, J. M., Frick, P. J., Shelton, K. K., \& Silverthorn, P. (1997). Ineffective parenting and childhood conduct problems: the moderating role of callous-unemotional traits. Journal of consulting and clinical psychology, 65(2), 301. 


\section{APPENDIX A. IRB APPROVAL}

\section{ACTION ON PROTOCOL APPROVAL REQUEST}

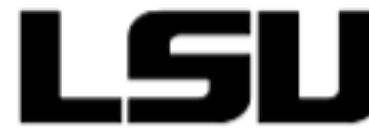

Institution al Review Board Dr. Dennis Landin, Chair 130 David Boyd Hall

TO: Paul Frick

Psychology

FROM: Dennis Landin

Chair, Institutional Review Board

Baton Rouge, LA 70803

P: 225.578 .8692

F: 225.578 .5983

irb@lsu.edu

DATE: October 17, 2017

RE: $\quad$ IRB\# 3940

TITLE: Rating Emotional Images

New Protocol/Modification/Continuation: NewProtocol

Review type: Full Expedited $\mathrm{X}$

Review date: 10/11/2017

Risk Factor: Minimal Uncertain Greater Than Minimal

Approved_ X Disapproved

Approval Date: 10/17/2017 Approval Expiration Date: 10/16/2018

Re-review frequency: (annual unless otherwise stated)

Number of subjects approved: $\underline{150}$

LSU Propos al Number (if applicable):

Protocol Matches Scope of Work in Grant proposal: (if applicable)

By. Dennis Landin, Chaiman

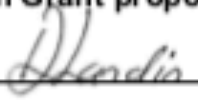

PRINCIPAL INVESTIGATOR: PLEASE READ THE FOLLOWING Continuing approval is CONDITIONAL on:

1. Adherence to the approved protocol, familiarity with, and adherence to the ethical standards of the Belmont Report, and LSU's Assurance of Compliance with DHHS regulations for the protection of human subjects*

2. Prior approval of a change in protocol, including revision of the consent documents or an increase in the number of subjects over that approved.

3. Obtaining renewed approval (or submittal of a termination report), prior to the approval expiration date, upon request by the IRB office (irrespective of when the project actually begins); notification of project termination.

4. Retention of documentation of informed consent and study records for at least 3 years after the study ends.

5. Continuing attention to the physical and psychological well-being and informed consent of the individual participants, including notification of new information that might affect consent.

6. A prompt report to the IRB of any adverse event affecting a participant potentially arising from the study.

7. Notification of the IRB of a serious compliance failure.

8. SPECIAL NOTE: When emailing more than one recipient, make sure you use bcc.

"All investigators and support staff have access to copies of the Belmont Report, LSU's Assurance with DHHS, DHHS (45 CFR 46) and FDA regulations goveming use of human subjects, and other relevant documents in print in this office or an our Wordd Wide Web site at htpp:/lwww. Isu.edu/irb 


\section{VITA}

Tatiana M. Matlasz, originally from Buffalo, New York, completed her Bachelor of Arts at the University of Buffalo (UB), State University of New York, where she double-majored in Psychology and Health and Human Services. During her time at UB, she worked in three different research labs studying the peer relationships of children and adolescents, the social nature of the self, and aggression and prosocial behaviors in preschoolers. Following her undergraduate training, she worked at Erie County Holding Center assisting with forensic evaluations and coordinating several research projects including one evaluating a residential treatment unit for male inmates with severe mental illness, and another implementing the Crisis Intervention Team (CIT) program in local police departments. Tatiana's interests in the development of severe psychopathology and forensic populations led her to her current work with Dr. Paul J. Frick at Louisiana State University where she is pursuing her doctorate in Clinical Psychology. 